\title{
Characterizing black carbon in rain and ice cores using coupled tangential flow filtration and transmission electron microscopy
}

\author{
A. Ellis ${ }^{1}$, R. Edwards ${ }^{1}$, M. Saunders ${ }^{2}$, R. K. Chakrabarty ${ }^{3}$, R. Subramanian ${ }^{4}$, A. van Riessen ${ }^{1}$, A. M. Smith ${ }^{5}$, \\ D. Lambrinidis ${ }^{6}$, L. J. Nunes ${ }^{1}$, P. Vallelonga ${ }^{7}$, I. D. Goodwin ${ }^{8}$, A. D. Moy ${ }^{9,10}$, M. A. J. Curran ${ }^{9,10}$, and \\ T. D. van Ommen ${ }^{9,10}$ \\ ${ }^{1}$ Physics and Astronomy, Curtin University, Perth, WA, Australia \\ ${ }^{2}$ Centre for Microscopy, Characterisation, and Analysis, The University of Western Australia, Perth, WA, Australia \\ ${ }^{3}$ Department of Energy, Environmental \& Chemical Engineering, Washington University in St. Louis, St. Louis, MO, USA \\ ${ }^{4}$ Department of Mechanical Engineering, Carnegie Mellon University, Pittsburgh, PA, USA \\ ${ }^{5}$ Australian Nuclear Science and Technology Organisation, Sydney, NSW, Australia \\ ${ }^{6}$ Research Institute for the Environment and Livelihoods, Charles Darwin University, Darwin, NT, Australia \\ ${ }^{7}$ Centre for Ice and Climate, Niels Bohr Institute, University of Copenhagen, Copenhagen, Denmark \\ ${ }^{8}$ Marine Climate Risk Group, Department of Environmental Sciences, Macquarie University, NSW, Australia \\ ${ }^{9}$ Australian Antarctic Division, Channel Highway, Kingston, TAS, Australia \\ ${ }^{10}$ Antarctic Climate and Ecosystems Cooperative Research Centre, University of Tasmania, Hobart, TAS, Australia
}

Correspondence to: A. Ellis (aja.a.ellis@gmail.com)

Received: 7 May 2015 - Published in Atmos. Meas. Tech. Discuss.: 19 June 2015

Revised: 11 September 2015 - Accepted: 14 September 2015 - Published: 29 September 2015

\begin{abstract}
Antarctic ice cores have been used to study the history of black carbon (BC), but little is known with regards to the physical and chemical characteristics of these particles in the remote atmosphere. Characterization remains limited by ultra-trace concentrations in ice core samples and the lack of adequate methods to isolate the particles unaltered from the melt water. To investigate the physical and chemical characteristics of these particles, we have developed a tangential flow filtration (TFF) method combined with transmission electron microscopy (TEM). Tests using ultrapure water and polystyrene latex particle standards resulted in excellent blanks and significant particle recovery. This approach has been applied to melt water from Antarctic ice cores as well as tropical rain from Darwin, Australia with successful results: TEM analysis revealed a variety of $\mathrm{BC}$ particle morphologies, insoluble coatings, and the attachment of $\mathrm{BC}$ to mineral dust particles. The TFF-based concentration of these particles has proven to give excellent results for TEM studies of BC particles in Antarctic ice cores and can be used for future studies of insoluble aerosols in rainwater and ice core samples.
\end{abstract}

\section{Introduction}

Carbonaceous aerosols emitted by combustion processes are comprised of black carbon (BC) and organic matter. These aerosols can stay suspended from days to weeks in the troposphere and for over a year in the stratosphere (Buseck and Adachi, 2008; Stohl and Sodemann, 2010). They impact the radiative, physical, and chemical properties of the atmosphere, affecting climate through direct optical effects and indirectly through changes in cloud formation and structure (Johnson et al., 2004). The contribution of BC to radiative forcing is significantly affected by particle shape, size, and mixing state, which is in turn affected by emission source and aging in the atmosphere (Jacobson, 2001; Moffet and Prather, 2009). Understanding the behavior of BC and other carbonaceous aerosols in the remote atmosphere is important for validating aerosol parameterization in general circulation models (Koch et al., 2009). Wet deposition through rain and snow is the primary removal process of $\mathrm{BC}$ from the atmosphere (Bond et al., 2013), and has a large impact on BC's atmospheric residence time and distribution (Hodnebrog et al., 2014). Furthermore, when deposited to highly reflective sur- 
faces such as snow, the presence of BC can decrease surface albedo and accelerate melting (Flanner et al., 2007; Hansen and Nazarenko, 2004; McConnell et al., 2007). Therefore, studies of BC in modern and historic rain, snow, and ice samples are needed to understand their modern atmospheric distribution and their presence in the paleo-atmosphere, and in turn to study their impact on paleoclimate forcing and future climate change.

Several methods exist for determining BC concentrations in the atmosphere, such as optical absorption methods, thermo-optical analysis, photoacoustic absorption spectroscopy, and aerosol mass spectrometry (Slowik et al., 2007). Single particle mass concentration and particle size can be measured in real-time by single particle intracavity laser-induced incandescence (SP2, Droplet Measurement Technologies, Boulder, CO, USA). Black carbon particles can also be characterized individually using electron microscopy (Pósfai et al., 1999). Many studies have measured BC abundance (as number and mass concentrations) in the atmosphere (Schwarz et al., 2006). Transmission electron microscopy (TEM) coupled with electron energy loss spectrometry (EELS) and energy-dispersive X-ray spectrometry (EDS) have long been used to determine the size, morphological, and elemental characteristics of atmospheric aerosols (Pósfai et al., 1999). Scanning transmission electron microscopy (STEM) coupled with EDS has been used to study aerosol particles (Utsunomiya and Ewing, 2003), with high resolution imaging and STEM EDS mapping revealing nanoscale inclusions in larger aerosols that would go unnoticed with traditional TEM imaging.

Previous studies have investigated BC mass concentrations in rainwater (Ohata et al., 2011; Torres et al., 2013), snow packs (Hegg et al., 2009; Warren and Clarke, 1990), and ice cores (Bisiaux et al., 2012; McConnell et al., 2007), but little data exists regarding the morphology, chemical composition, and insoluble coatings of $\mathrm{BC}$ particles in rain and snow. This is particularly true of aged, long-range transported particles that have been deposited at the polar ice caps.

To the best of our knowledge, only one study has previously studied the morphology of carbonaceous aerosols in precipitation. Murr et al. (2004) analyzed particles in ice cores from the Greenland ice cap by melting the ice and depositing $180 \mathrm{~mL}$ of sample on a $5 \mathrm{~mm}$ TEM grid, a few microliters at a time. As made evident by this process, isolating these particles for characterization is technically challenging, especially in ultra-clean Antarctic ice, where their abundance is often less than $0.1 \mu \mathrm{g} \mathrm{kg}^{-1}$ (Bisiaux et al., 2012). As Antarctic ice cores have substantially lower BC concentrations than that observed in Greenland ice, larger sample volumes ( $>1 \mathrm{~L}$ melt water) are necessary to acquire sufficient particles for characterization, making this drop-by-drop method impractical. Salts and other dissolved species cause additional problems with the drop-by-drop method because they are also deposited on the grid, coating it with large amounts of unwanted material. When concentrated on TEM grids, these precipitated particles can hinder the detection and analysis of BC simply by obscuring particle morphology, especially when $\mathrm{BC}$ is present in ultra-trace concentrations.

An ideal preconcentration method for insoluble BC particles in polar ice should be reasonably quick, concentrate large volumes of ice melt water, remove salts, and keep the particles in motion to limit aggregation. Tangential flow filtration (TFF) is a technique that uses a continuous flow of solution tangentially across a filter membrane to avoid sample build-up on the surface of the membrane (and subsequent sample loss). Hollow fiber filters have been employed to concentrate environmental water samples (Benner et al., 1997; Giovannoni et al., 1990) as well as nanoparticles for pharmaceutical applications (Dalwadi et al., 2005). TFF has a high particle recovery, can concentrate large sample volumes (>1 L) without membrane fouling, does not cause nanoparticle aggregation, and can preserve fragile aerosol structures (Benner et al., 1997; Dalwadi et al., 2005). An important benefit of TFF to the study of BC particles is that it can concentrate particles whilst removing dissolved salts and other species, depending on the pore size of the filter.

To study individual BC particles and other carbonaceous aerosols in global precipitation, we investigated the use of TFF to concentrate BC prior to analysis by TEM. Particle recovery rates and blanks were investigated using polystyrene latex (PSL) particle standards and ultrapure water. Test samples included tropical rainwater from Darwin, Australia as well as Antarctic ice cores. The rainwater provided an example of equatorial wet deposition of particles, whereas Antarctic ice provides both a modern example of polar deposition as well as a historical record of these particles in the global atmosphere.

\section{Methodology}

\subsection{Clean room laboratory environment}

Sample preparation and cleaning of laboratory and field equipment was performed in the Trace Research and Advanced Clean Environment (TRACE) laboratory at Curtin University. The TRACE facility is a $450 \mathrm{~m}^{2}$ clean-air laboratory facility described by Burn et al. (2009). The facility includes a large positive pressure clean-air exclusion space (ISO Class 5) housing five smaller clean-air laboratory modules (ISO Class 4) including a cold laboratory module. With the exception of the cold laboratory module, the modules draw clean air from the exclusion space through a series of high-efficiency particle air (HEPA) filters in the module roof. Module air passes through the floor and either recirculates back into the module and the exclusion space or is exhausted through the base of clean air hood. Air inside the cold laboratory module is filtered by a recirculating cryogenic air filtration HEPA system. The $\mathrm{BC}$ concentration in the exclusion space air was determined using a single-particle soot photometer (SP2) and found to be less than $1 \mathrm{BC}$ particle $\mathrm{m}^{-3}$ 
for particles with a mass equivalent diameter range of 70 to $700 \mathrm{~nm}$ (assuming a constant density of $1.8 \mathrm{~g} \mathrm{cc}^{-1}$ as in Schwarz et al., 2013).

Mechanical decontamination of ice core samples was conducted in the TRACE cold laboratory module at $-12^{\circ} \mathrm{C}$. All other sample preparation and TEM grid preparation activities were conducted in a clean-air bench inside a laboratory module.

The modules are fitted with an ultrapure water (UP, $\rho>18.2 \mathrm{~m} \Omega$ ) system fed by a laboratory-wide reverse osmosis and deionized water supply. This water was used for cleaning all laboratory benches, fittings, tubing, and plastic ware. Melted samples were kept in Teflon or low-density polyethylene (LDPE) bottles, filled and rinsed multiple times with UP water. All surfaces were cleaned with UP water prior to sample decontamination.

\subsection{Reagents and materials}

\subsubsection{Blanks}

The entirety of this concentration method was blank-tested with laboratory-made UP ice. The blank ice was made by freezing UP water in a cleaned $3 \mathrm{~L}$ perfluoro alkoxyalkane container (PFA, Savillex). The ice was removed from the container, cut into rectangles on a clean band saw in the cold laboratory module, and bagged in plastic layflat bags. This was to mimic the condition and treatment of the Antarctic ice core samples.

\subsubsection{Polystyrene latex particles}

$200 \mathrm{~nm}$ polystyrene latex (PSL) spheres (SPI Supplies, Structure Probe, Inc., West Chester, PA) were used to test the filtration and microscopy method, as they can be suspended in water and are readily identified on TEM grids.

\subsubsection{Filters}

$50 \mathrm{kD}$ pore size modified polyethersulfone (mPES) Hollow Fiber Filters (HFFs, Spectrum Laboratories, California) with $20 \mathrm{~cm}^{2}$ membrane surface area, gamma irradiated for sterility, were used to concentrate samples. The $50 \mathrm{kD}(\sim 10 \mathrm{~nm})$ pore size was selected to retain as many particles as possible while minimizing filtration time. Any soluble species or particulates smaller than $10 \mathrm{~nm}$ are removed from the solution during filtration, including dissolved salts.

\subsubsection{Grids}

The TEM grids used for the study were $\mathrm{SPI}^{\mathrm{TM}} 300$-mesh gold grids with a continuous (non-porous) $\mathrm{SiO}_{2} / \mathrm{SiO}$ support film. Gold was selected due to its resistance to corrosive UP water. Additionally, the carbon coating on the traditional copper TEM grids had irregularities that made distinguishing the actual carbonaceous sample difficult, and silicon dioxide coat- ings did not interfere with identification of carbonaceous particles using EDS spectra.

\subsection{Instrumentation}

A scanning electron microscope (SEM) was used to look at TEM grids prior to TEM analysis, to verify that sufficient particles were present on the grid. Scanning electron microscopy was performed with a Zeiss Neon 40EsB FIBSEM operated at $5 \mathrm{kV}$, located at Curtin University's Microscopy $\&$ Microanalysis Facility.

The transmission electron microscopy was performed on a FEI Titan G2 80-200 TEM/STEM with ChemiSTEM Technology, which incorporates scanning transmission electron microscopy (STEM) with $\sim 1 \mathrm{~nm}$ resolution EDS mapping. Samples were imaged using both TEM and STEM, both operating at $80 \mathrm{kV}$. This instrument is located at the University of Western Australia. Additional imaging and spectroscopy was performed on a JEOL 2100 TEM operated at $120 \mathrm{kV}$ and equipped with a Gatan Tridiem energy filter for EELS and energy filtered transmission electron microscopy (EFTEM) work.

\subsection{Samples}

\subsubsection{Ice core samples}

The DSS0506 ice core samples used in this study were collected in the 2005-2006 austral summer from Law Dome, East Antarctica. The ice core drilling location was at Dome Summit South (DSS), and provides overlapping ice core to the main DSS ice core $\left(66^{\circ} 46^{\prime} 11^{\prime \prime} \mathrm{S}, 112^{\circ} 48^{\prime} 25 / / \mathrm{E}, 1370 \mathrm{~m}\right.$ elevation). Ice and snow from this site have been the subjects of a large number of studies (Burn-Nunes et al., 2011; Curran et al., 1998; Etheridge et al., 1996; Palmer et al., 2001; Pedro et al., 2012; Vallelonga et al., 2002; van Ommen and Morgan, 1996, 2010). The flux of BC deposition at the same sampling site in Law Dome, East Antarctica has been quantified using an SP2 (Bisiaux et al., 2012). The ice core used in this study was cut longitudinally into two parallel sections, $1 \mathrm{~m}$ long with a $5 \mathrm{~cm}$ by $5 \mathrm{~cm}$ cross-section. One section was used for measuring trace ion chemicals and stable isotopes, and the matching section was transported to the TRACE facility at Curtin University for BC studies. The ice was dated by matching the dissolved ion chemistry and water stable isotope records $\left(\delta^{18} \mathrm{O}\right)$ to the main DSS ice core record to produce a depth age scale for DSS0506. The main DSS ice core record was dated using annual layer counting and identification of volcanic horizons (Plummer et al., 2012). The cores used in this study are DSS0506-38U from $70.5 \mathrm{~m}$ and dated to $1930 \mathrm{CE}$, DSS0506-69U from $131.5 \mathrm{~m}$ and dated to $1838 \mathrm{CE}$, and DSS0506-93U from $178.3 \mathrm{~m}$ and dated to 1759 CE. Approximately $1 \mathrm{~cm}$ of ice was removed from all sides during decontamination, resulting in $\sim 1.5$ to $2 \mathrm{~L}$ of melt water. 


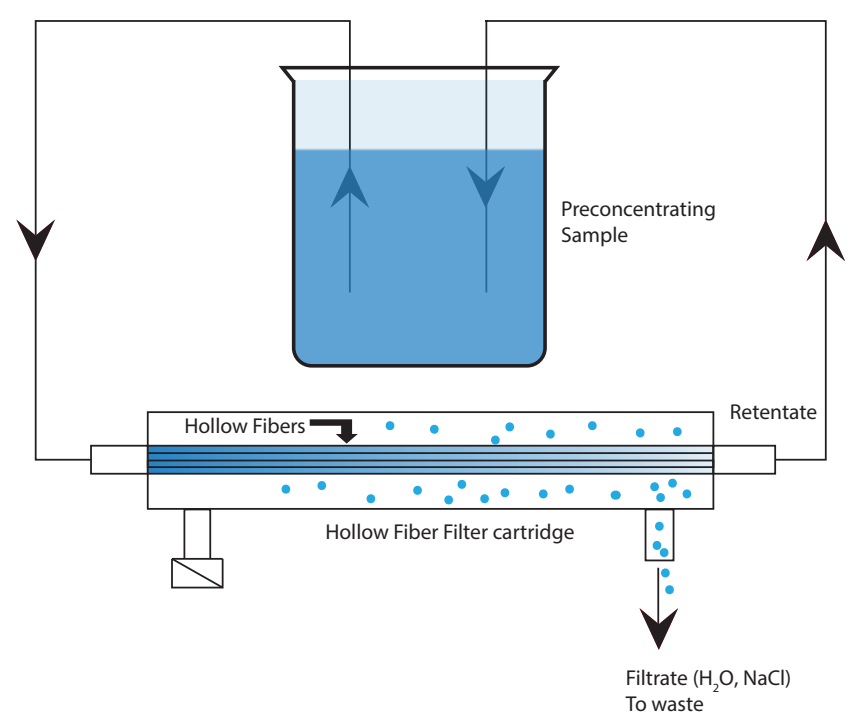

Figure 1. Tangential flow filtration setup for concentration of rain or melted ice core sample $\mathrm{H}_{2} \mathrm{O}$. Water sample recirculates through the hollow fiber filter, with $\mathrm{H}_{2} \mathrm{O}$ and dissolved species removed through open side port of filter cartridge.

\subsubsection{Rain samples}

Monsoon rain samples were collected in Darwin, in tropical northern Australia. The region experiences a dry season (May-November) and a monsoonal wet season in the summer months (December-March) (Holland, 1986; Kaars et al., 2000), and is in close proximity to equatorial Asian biomass burning as well as annually occurring northern Australian bushfires. The samples used to test this method were collected on 8 and 11 April 2014, during the end of the wet period in Darwin when large volumes of rain could be collected in short periods of time. Rain was collected using an UP water cleaned Teflon funnel with a $1 \mathrm{~L}$ cleaned low density polyethylene bottle (LDPE, Nalgene) attached via a threaded cap. The funnel was placed on a bucket in an open field, with no overhead obstructions.

\subsection{Decontamination and concentration method}

The ice core decontamination procedure was adapted from the methods of Burn et al. (2009), Candelone et al. (1994), and Edwards et al. (2006), using materials described in Sect. 2.1 of this paper.

Ice core sections were placed on a cleaned plastic covered surface in the TRACE facility cold laboratory module. The exterior of the ice core was progressively removed and discarded using an acid-cleaned stainless steel chisel. The chisel was cleaned with $2 \%$ nitric acid before use and rinsed with UP water in-between different ice core samples. Approximately $5 \mathrm{~mm}$ were removed from all surfaces of the ice using the chisel. After removing the exterior, the ice samples were transferred into an acid-cleaned colander made from a $3 \mathrm{~L}$ fluorinated high-density polyethylene bottle with large holes drilled into the bottom. The colander was cleaned in $10 \%$ nitric acid and rinsed with UP water before use. The ice samples were then rinsed with large amounts of UP water to remove a further $\sim 5 \mathrm{~mm}$ from all surfaces. Finally the samples were removed from the colander with acid-cleaned polypropylene tongs and transferred into a $3 \mathrm{~L}$ perfluoro alkoxyalkane container. Ice pieces were added periodically to the perfluoro alkoxyalkane melt water container over the course of the filtration, as to keep the sample cold while filtering to avoid possible aggregation. Rain samples were filtered directly from the sampling container (1 L LDPE Nalgene bottle).

The TFF setup consisted of a recirculating HFF connected to a multichannel peristaltic pump (Ismatec IPC pump, IDEX Health \& Science), detailed in Fig. 1. Samples were pumped through filters with standard PVC two-stop pump tubing and PFA tubing.

During concentration, sample water was recirculated from the bottle using the peristaltic pump, through a HFF, and then back into the sample bottle. One of two side ports on the HFF was left open over a waste container to allow filtrate to be removed with little backpressure, as backpressure on the filtrate removal line would have slowed the filtration rate. The sample bottle was elevated above the filter, and the height difference between filter and sample bottle was used to increase or decrease backpressure on the filter, speeding or slowing filtrate removal as required. Filtrate was removed at $250 \mathrm{~mL} \mathrm{~h}^{-1}$, resulting in a concentration of $2 \mathrm{~L}$ to $1.5 \mathrm{~mL}$ in approximately $8 \mathrm{~h}$.

The pump direction was periodically reversed, with the sample moving backwards through the filter, for $\sim 5 \mathrm{~s}$ to avoid particle build-up on the membrane surface. The filter is also backflushed immediately prior to collecting the final concentrated sample with $1 \mathrm{~mL}$ of water (Fig. 2) to remove any additional particles from the membrane. Samples were concentrated to $1.5 \mathrm{~mL}$ in the sample bottle, transferred to a cleaned polypropylene centrifuge vial, and gently shaken to avoid particle size separation. Concentrated samples were then deposited on $5 \mathrm{~mm}$ TEM grids, $30 \mu \mathrm{L}$ at a time using a clean PP pipette tip. The TEM grid was held elevated off the laboratory bench surface by SPI stainless steel tweezers in the TRACE module clean air hood at room temperature $\left(\sim 22^{\circ} \mathrm{C}\right)$ while the sample was evaporating down. Each $30 \mu \mathrm{L}$ drop was left to evaporate fully between drops, depositing particles on the surface of the grid. To avoid particle separation in the solution, the sample vial was shaken immediately before each deposition. The sample vial was stored at $2^{\circ} \mathrm{C}$ between drops. Approximately $0.18 \mathrm{~mL}$ of sample was deposited to each grid.

\subsection{Particle characterization using electron microscopy}

Insoluble particles were characterized using electron microscopy, initially to check for sample recovery, and eventu- 


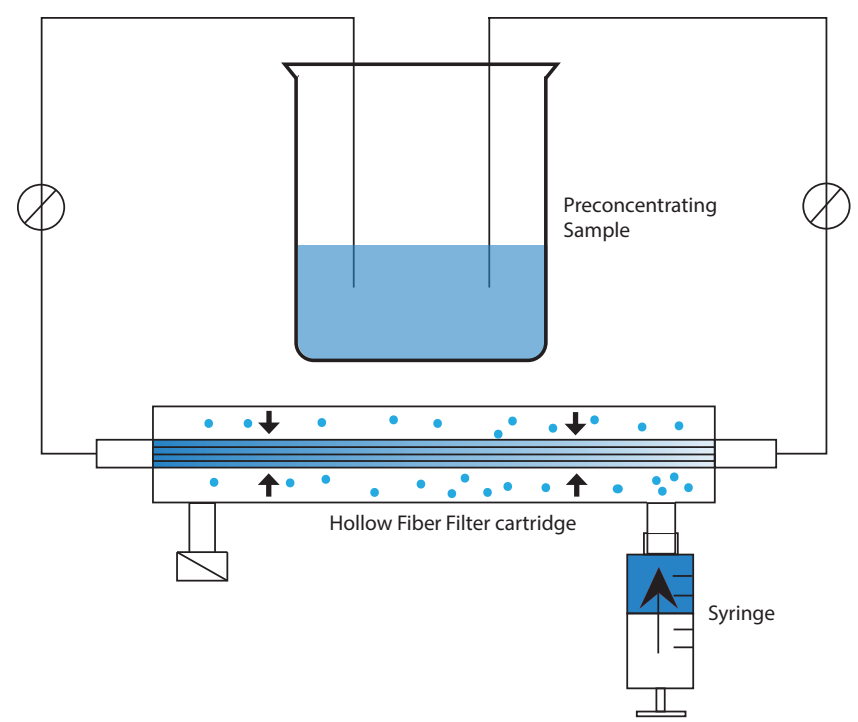

Figure 2. Backflush of hollow fiber filter membrane setup, performed by stopping the peristaltic pump and injecting $1 \mathrm{~mL}$ of ultrapure water into the open side port using a syringe.

ally for quantification of particle size, morphology, and composition. During recovery method development, secondary electron imaging in the SEM was used to look for particles remaining on filters as well as for inspecting TEM grids for particles recovered through filtration.

The silicon-coated grid exhibited some charging effects under the electron beam, and damaged squares of film (i.e., holes from handling with tweezers) could collapse completely when imaged in normal TEM mode. Often, spreading the beam out over a large section of grid and waiting a few minutes before imaging at higher magnification could prevent sample jumping. Film squares with large objects, such as bacteria or dust particles $>10 \mu \mathrm{m}$, were more susceptible to complete collapse from charging.

On the TEM, the entire area of each grid was initially surveyed at $200-500 \times$ magnification to locate particles, which were then imaged at higher magnifications and EELS/EDS spectra were acquired to characterize particle types. Particles were imaged at $\sim 10000 \times$ magnification for complex, larger aggregates, and 100000-200 000× magnification for fine structure and individual particle morphology. Seemingly empty portions of the grid were also surveyed at higher magnification, to verify that potential deposits of smaller particles were not overlooked.

$\mathrm{BC}$ was identified using various TEM results, including spherule aggregate structure, the presence of carbon peaks in EDS or EELS spectra, size of primary spherules $(\sim 30 \mathrm{~nm})$, and "onion-ring" structure of spherules. STEM imaging and EDS were used to preserve beam-sensitive structures, such as coatings on the particles. EFTEM elemental maps were acquired using the traditional three-window technique using energy windows adjusted to provide optimum signal-to-noise (Brydson, 2001).

\subsection{Testing the cleanliness of the system}

As the concentration method will concentrate both sample and contaminants, blanks were tested on each major step of the procedure to exclude the possibility of procedural contamination. Unused TEM grids were scanned prior to use for sampling. To test the cleanliness of the water, blank UP water was concentrated and deposited on TEM grids for imaging. Laboratory-made UP water blank ice was decontaminated and concentrated using the method in Sect. 2.5. The TEM samples were prepared from the concentrated solution.

\section{Results and discussion}

\subsection{Blanks}

No BC was found on any of the unused TEM grids or in any of the UP water tests. An UP water blank on the hollow fiber filter after filtering a rain sample was inspected on the TEM, and there was little evidence of cross contamination. Three, $\sim 500 \mathrm{~nm}$ alumina silicate dust particles were found on the entire grid, surveying at $500 \times$ magnification.

\subsection{Tangential flow filtration}

Using TFF, the ice core samples were concentrated from an average initial volume of $\sim 2 \mathrm{~L}$ to a final volume of $1.5 \pm 0.1 \mathrm{~mL}$, a factor of $\sim 1300$. The concentration factor varied slightly due to the initial volume of the ice core melt water, which was different for each ice core sample used. This was due to variations in the size of each ice core.

The TFF method was tested with polystyrene latex (PSL) spheres $(200 \mathrm{~nm}$ diameter). A prepared standard of $1 \mathrm{~L}$ of $1 \mu \mathrm{gg}^{-1}$ (1 ppb) PSL particles was concentrated from $1 \mathrm{~L}$ to $\sim 1.5 \mathrm{~mL}$ using the method in Sect. 2.5 , resulting in a final concentration of $\sim 670 \mu \mathrm{g} \mathrm{kg}^{-1}$. This concentrated standard was then deposited on a $\mathrm{SiO}_{2} / \mathrm{SiO}$ coated TEM grid. SEM images of the prepared sample grid showed significant sample recovery for characterization, with areas of the grid completely obscured with spheres (Fig. 3).

Using an average BC concentration of $0.08 \mu \mathrm{g} \mathrm{kg}^{-1}$ from the same Law Dome location in Antarctica (Bisiaux et al., 2012) and a concentration ratio of $2 \mathrm{~L}$ to $1.5 \mathrm{~mL}$, the final $\mathrm{BC}$ concentration of the ice core samples was $\sim 100 \mu \mathrm{g} \mathrm{kg}^{-1}$. A number of methods were tested to extract particles from water samples in this study, and these methods are detailed in Appendix A. Comparison of this TFF method with the "failed" methods in Appendix A indicate that particle recovery from TFF is more effective at both concentrating particles and keeping particles suspended in a solution, which can then be deposited on a TEM grid for characterization. Given that the melting of snow samples does not affect the 


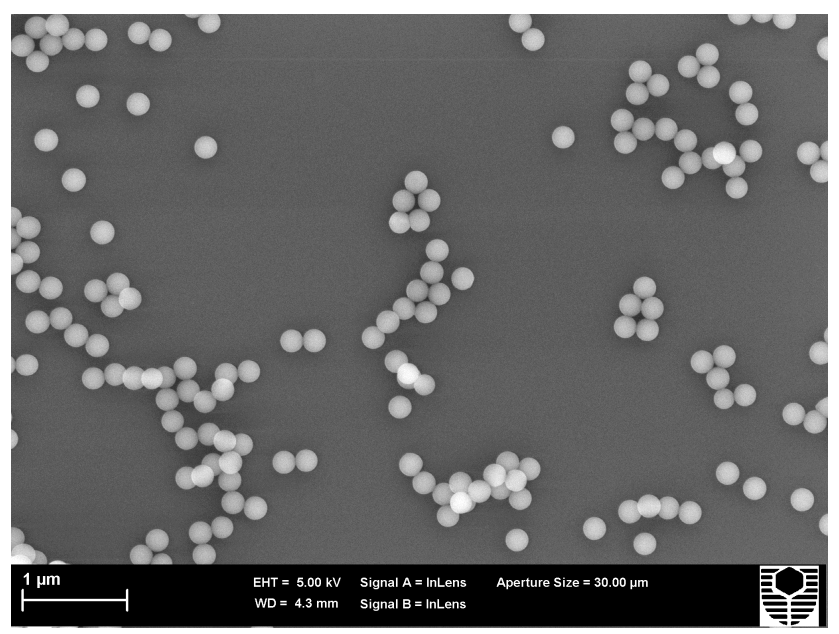

Figure 3. SEM image of PSL spheres from concentration method test on $\mathrm{SiO}_{2} / \mathrm{SiO}$ coated grid surface, concentrated from 1 to $\sim$ $667 \mu \mathrm{g} \mathrm{kg}^{-1}$ using TFF.

size distribution of BC aerosols (Schwarz et al., 2013), the only information lost in the melting of the ice core would be any possible soluble constituents of the $\mathrm{BC}$ aerosols, such as soluble coatings.

\subsection{Transmission electron microscopy}

Results presented from this study pertaining to the relative and absolute abundance of different particle types are qualitative only, because a statistically rigorous survey of all particles on the grid was not completed. Nevertheless, the images included in this paper have been chosen to be representative of particles commonly seen while scanning the grid.

Sample charging on the $\mathrm{SiO}_{2} / \mathrm{SiO}$-coated grids caused difficulty with TEM and STEM imaging, as the grid would periodically shift abruptly while collecting an image. The silicon and oxygen provided a useful background when looking for carbon in EDS and EELS spectra, but a carbon-coated grid would be more stable for high-resolution imaging on the nanometer scale.

Black carbon aggregates were readily identified by their onion structure and morphology on TEM grids from both rain samples and ice core samples. In addition, STEM EDS revealed coatings and inclusions in the aggregates that would have otherwise been overlooked. STEM EDS also preserved beam-sensitive sample, including nitrogen and oxygen coatings up to $5 \mathrm{~nm}$ thick on the BC aggregates (Fig. 4).

Various mineral dust particles were also successfully identified in both sample suites via imaging coupled with EELS and EDS analysis (Figs. 5 and 6) and EELS and EFTEM analysis helped characterize complex dust particles containing $\mathrm{Al}, \mathrm{Si}, \mathrm{Fe}$, and $\mathrm{C}$ (Fig. 6). The mixing of $\mathrm{BC}$ and other particulates shown in Figs. 5-7 is significant, as internal mixing of BC with other particles such as dust can affect their radiative forcing (Clarke et al., 2004; Scarnato et al., 2015).
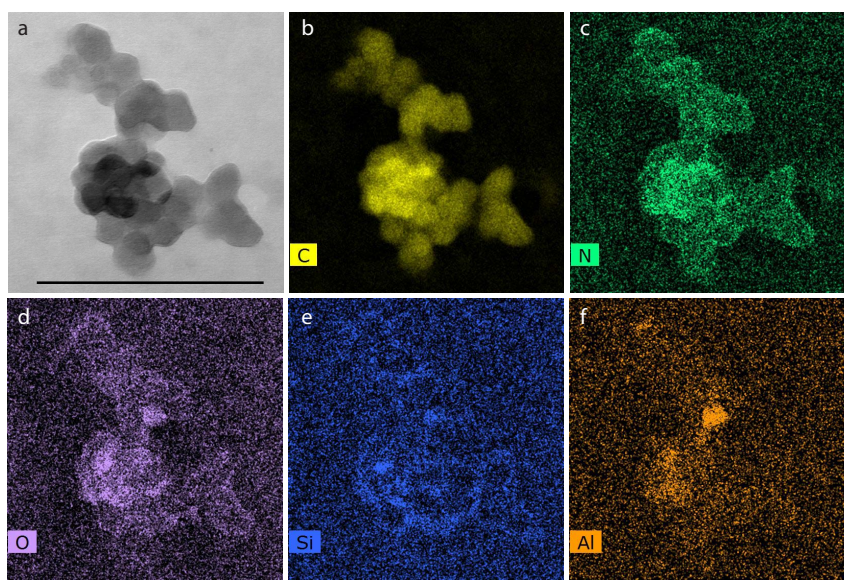

Figure 4. An example of a $\mathrm{BC}$ aggregate with nitrogen and oxygen coating and aluminum-rich silicate inclusions from Law Dome, Antarctica ice core dated to 1759 CE. (a) STEM image, scale bar $=$ $300 \mathrm{~nm}$. (b-f) a series of STEM EDS maps for C, N, O, Si and Al, respectively. Element maps shown are from same field of view as image (a).

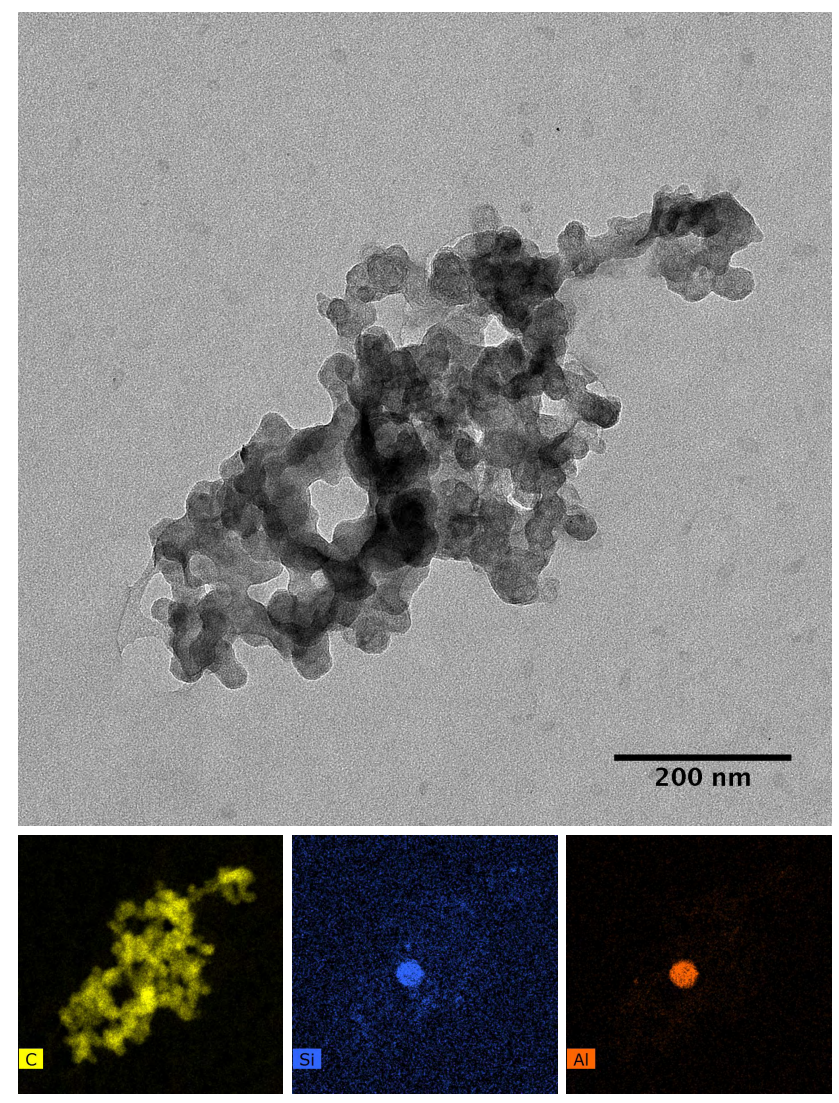

Figure 5. TEM image of a particle from Darwin rain sample collected 11 April 2014, with accompanying STEM EDS maps of carbon, silicon, and aluminum. Element maps are from the same field of view as the TEM image. 


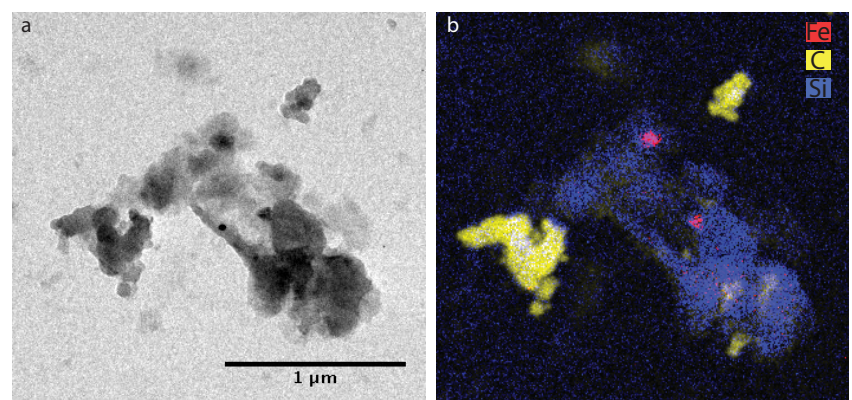

Figure 6. Examples of particles concentrated from a Law Dome, Antarctica ice core dated to $1930 \mathrm{CE}$. (a) TEM image and (b) EFTEM map of a complex aggregate particle where red is iron, blue is silicon, and yellow is carbon.

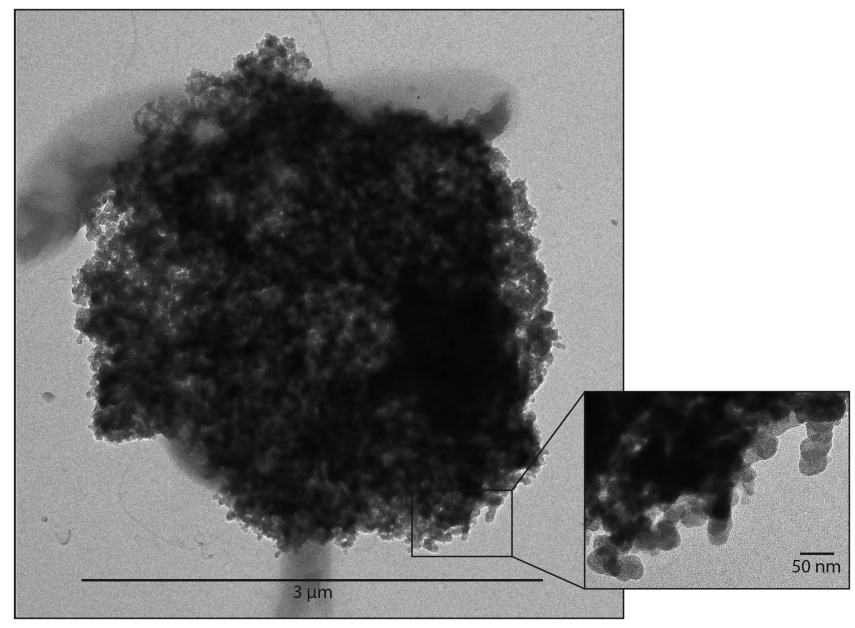

Figure 7. Aged superaggregate from Darwin rain sample collected 8 April 2014. Inset is of an enlarged section of aggregate, showing individual $\mathrm{BC}$ sphere structure.

STEM-EDS can distinguish variations in BC composition that may routinely be overlooked.

Both the rain and ice cores had a large quantity of BC particles, with graphitic carbon "onions" of $\sim 30 \mathrm{~nm}$ in diameter aggregated into larger particles of $\sim 80$ to $>1000 \mathrm{~nm}$ in diameter. These particles often showed association with aluminosilicate dust particles (Fig. 5). Black carbon particles in both the rain and ice cores appeared to be significantly aged in the atmosphere as indicated by the collapsed structure of the carbon spherules (Figs. 4-7).

The surveys in this study permitted qualitative comparisons between samples. For example, in general, the rain samples had many larger BC aggregates (> $200 \mathrm{~nm}$ ), whereas $\mathrm{BC}$ aggregates found in the ice cores were significantly smaller $(\sim 100 \mathrm{~nm})$ and displayed a much more compact structure. Rain samples also contained numerous superaggregates as described in (Chakrabarty et al., 2014). These superaggregates were $>1 \mu \mathrm{m}$ in diameter and were absent in the ice cores (Fig. 7). Given the high particle yields from the TFF concentration method, it is anticipated that more systematic TEM surveys could facilitate more statistically robust data on particle type and size distributions. However, this is beyond the scope of this study.

The tangential flow filtration concentration method has been used to preserve fragile structures of particles and to avoid aggregation of nanoparticles. Nevertheless, disaggregation, aggregation, and aggregate collapse are still possible outcomes of the method. However, we see no obvious evidence that these factor significantly into the results.

Tests of bond strength between carbon spheres in BC show that aggregates are unlikely to fragment into smaller units (Rothenbacher et al., 2008). Hence, disaggregation from this method is unlikely. Additionally, both the rain samples and the ice core melt water samples were processed in an identical way, including the filtration technique to concentrate the samples and the evaporation technique to deposit particles on the TEM grids. Both rain and ice core samples contained significant variations in particle size, including large amounts of smaller BC aggregates $(\sim 100 \mathrm{~nm})$. This variety suggests that method-induced aggregation did not result in significant changes to the particle population.

The collapsed structure of the black carbon aggregates seen in the ice core samples is supported by reports of BC aging in the atmosphere (Johnson et al., 1991; Li et al., 2003; Martins et al., 1998). The BC contained in Antarctic ice cores has aged significantly from emission to deposition and would therefore likely contain collapsed aggregates. As BC is wet deposited in the rain samples, the particles are likely hydrophilic. The transition from hydrophobic to hydrophilic is a result of atmospheric aging (Stier et al., 2006), suggesting that the $\mathrm{BC}$ in rain has also aged significantly before deposition and will contain collapsed aggregates as well.

While post-deposition processes within the glacier cannot be ruled out, volume equivalent diameters of BC particles found in the ice (Bisiaux et al., 2012) are similar to those determined over the remote Southern Ocean by the HIPPO project (Schwarz et al., 2010). Snow densification and ice metamorphosis are more likely to aggregate BC particles into crystal junctions. If this were significant, larger particles would be expected rather than smaller ones. The differences between the $\mathrm{BC}$ found in rain and Antarctic ice likely reflect the loss of large aggregates during long-distance transport to Antarctica.

\section{Conclusion}

The results presented herein clearly show that the combination of tangential flow filtration and transmission electron microscopy methods provides an effective way to characterize both centuries-old atmospheric aerosols preserved in Antarctic ice and modern aerosols in rain water. Using a clean decontamination procedure and tangential flow filtration method, aerosols in rain and Antarctic ice have been concentrated by a factor of $\sim 1300$. Tangential flow filtration 
method tests with polystyrene latex particle standards have shown sufficient particle recovery for transmission electron microscopy characterization, and blank tests with ultrapure laboratory ice indicate that this process does not introduce any measureable contaminants. The results in this paper indicate that black carbon particles can form around or aggregate with dust and other mineral particulates, and aggregates can develop thin $(<5 \mathrm{~nm})$ insoluble coatings of nitrogen and oxygen.
An important potential future development includes the possibility of quantification of particle sizes and types through systematic grid surveys of samples prepared from specific ice core depths. This type of survey could provide a statistically significant analysis of black carbon morphologies and chemical compositions in Antarctic ice, which could potentially reveal changes in black carbon over time. 


\section{Appendix A: Unsuccessful concentration methods}

\section{A1 Drop by drop evaporation without preconcentration}

Murr et al. (2004) used a drop-by-drop method to deposit Greenland ice core melt water on a TEM grid, $\sim 3 \mu \mathrm{L}$ at a time. The drop-by-drop method might work on higher concentration samples (i.e., temperate ice cores or snow samples), but due to low concentrations of $\mathrm{BC}$ in Antarctic ice cores, characterization of the particles necessitates concentrating the melted ice core prior to depositing it on a TEM grid. To preserve the largest amount of particles, the sample should be processed as quickly as possible. The longer the sample sits melted, the greater chance of losing black carbon to aggregation or diffusion to the walls of the sample container. Depending on concentration of BC in sample, the drop-by-drop method would require a significant amount of sample deposition to grid before there are sufficient particles to image ( $\sim 1 \mathrm{~L}$, deposited $3 \mu \mathrm{L}$ at a time), potentially losing particles in the sample as each drop dries on the grid.

\section{A2 Vacuum ablating ice}

We attempted to vacuum ablate ice, to avoid putting the $\mathrm{BC}$ into solution where it might lose soluble portions of the structure. This was tested on a Christ Alpha 1-2 LD Freeze Dryer. It took approximately 6 hours for a $5 \mathrm{~cm}^{3}$ piece of blank ice to halve in size. A substantially larger ice core sample is required to obtain sufficient particles for characterization in low-concentration Antarctic ice.

\section{A3 Anopore filtration followed by back flushing}

Preconcentration was attempted using a $200 \mathrm{~nm}$ pore-size Anopore polycarbonate filter. An ice core sample was melted and filtered using the peristaltic pump and an Anopore filter in a Teflon filter holder. The filter was then backflushed with $\sim 5 \mathrm{~mL}$ of Milli-q water using a syringe.

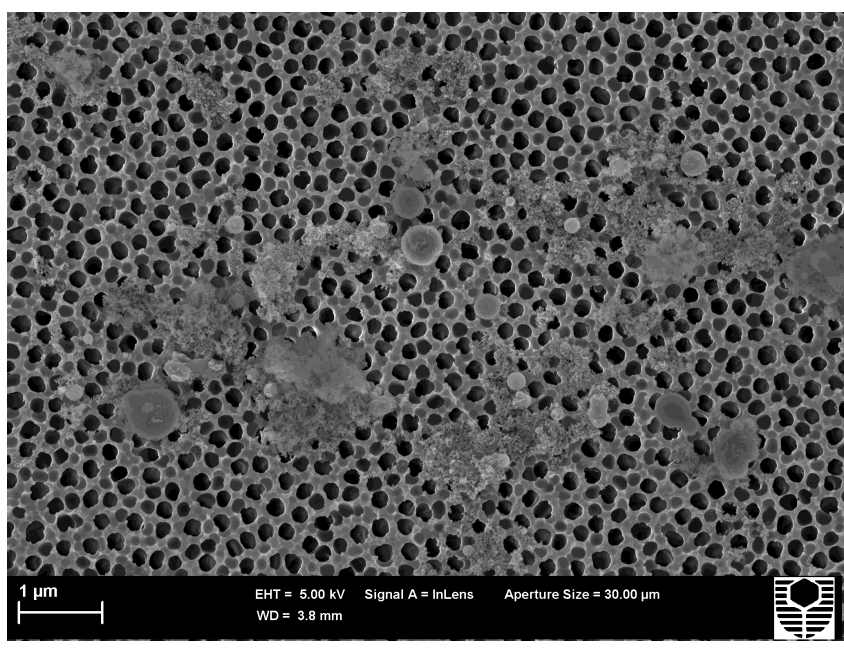

Figure A1. SEM image of Anopore filter after filtering $1 \mathrm{~L}$ of ice core melt water, and backflushing the filter to remove filtered particles.

SEM imaging of TEM grids made from the backflushed sample solution indicates only a small fraction of particles were recovered from the filter. Further SEM imaging of the filter itself showed large amounts of particulates remained stuck to the filter surface and were not removed through backflushing (Fig. A1). Ultrasonication was not used to dislodge particles due to the possible separation of aerosol aggregates, compromising the characterization results of $\mathrm{BC}$ aggregates. This could be a useful method for a lowermagnification scanning electron microscopy (SEM) study of larger aerosols, but large pore size and complicated filter structure makes locating smaller BC aggregates difficult. 
Acknowledgements. This work was supported by Australian Antarctic Sciences Grant 4144. The authors acknowledge the use of Curtin University's Microscopy \& Microanalysis Facility, whose instrumentation has been partially funded by the University, State and Commonwealth Governments. The authors acknowledge the facilities, and the scientific and technical assistance of the Australian Microscopy \& Microanalysis Research Facility at the Centre for Microscopy, Characterisation \& Analysis, The University of Western Australia, a facility funded by the University, State, and Commonwealth Governments.

Edited by: P. Herckes

\section{References}

Benner, R., Biddanda, B., Black, B., and McCarthy, M.: Abundance, size distribution, and stable carbon and nitrogen isotopic compositions of marine organic matter isolated by tangential-flow ultrafiltration, Mar. Chem., 57, 243-263, doi:10.1016/S03044203(97)00013-3, 1997.

Bisiaux, M. M., Edwards, R., McConnell, J. R., Curran, M. A. J., Van Ommen, T. D., Smith, A. M., Neumann, T. A., Pasteris, D. R., Penner, J. E., and Taylor, K.: Changes in black carbon deposition to Antarctica from two high-resolution ice core records, 1850-2000 AD, Atmos. Chem. Phys., 12, 4107-4115, doi:10.5194/acp-12-4107-2012, 2012.

Bond, T. C., Doherty, S. J., Fahey, D., Forster, P., Berntsen, T., DeAngelo, B., Flanner, M., Ghan, S., Kärcher, B., and Koch, D.: Bounding the role of black carbon in the climate system: a scientific assessment, J. Geophys. Res.-Atmos., 118, 5380-5552, 2013.

Brydson, R.: Electron Energy Loss Spectroscopy, Bios in association with the Royal Microscopical Society, Oxford, 2001.

Burn, L. J., Rosman, K. J. R., Candelone, J.-P., Vallelonga, P., Burton, G. R., Smith, A. M., Morgan, V. I., Barbante, C., Hong, S., and Boutron, C. F.: An ultra-clean technique for accurately analysing $\mathrm{Pb}$ isotopes and heavy metals at high spatial resolution in ice cores with sub-pg $\mathrm{g}(-1) \mathrm{Pb}$ concentrations, Anal. Chim. Acta, 634, 228-236, doi:10.1016/j.aca.2008.11.067, 2009.

Burn-Nunes, L. J., Vallelonga, P., Loss, R. D., Burton, G. R., Moy, A., Curran, M., Hong, S., Smith, A. M., Edwards, R., Morgan, V. I., and Rosman, K. J. R.: Seasonal variability in the input of lead, barium and indium to Law Dome, Antarctica, Geochim. Cosmochim. Ac., 75, 1-20, doi:10.1016/j.gca.2010.09.037, 2011.

Buseck, P. R. and Adachi, K.: Nanoparticles in the atmosphere, Elements, 4, 389-394, doi:10.2113/Gselements.4.6.389, 2008.

Candelone, J.-P., Hong, S., and Boutron, C. F.: An improved method for decontaminating polar snow or ice cores for heavy metal analysis, Anal. Chim. Acta, 299, 9-16, doi:10.1016/00032670(94)00327-0, 1994.

Chakrabarty, R. K., Beres, N. D., Moosmuller, H., China, S., Mazzoleni, C., Dubey, M. K., Liu, L., and Mishchenko, M. I.: Soot superaggregates from flaming wildfires and their direct radiative forcing, Sci. Rep. 4, 5508, doi:10.1038/srep05508, 2014.

Clarke, A. D., Shinozuka, Y., Kapustin, V. N., Howell, S., Huebert, B., Doherty, S., Anderson, T., Covert, D., Anderson, J., Hua, X., Moore, K. G., McNaughton, C., Carmichael, G., and Weber, R.:
Size distributions and mixtures of dust and black carbon aerosol in Asian outflow: Physiochemistry and optical properties, J. Geophys. Res.-Atmos., 109, D15S09, 2004.

Curran, M. A., Van Ommen, T. D., and Morgan, V.: Seasonal characteristics of the major ions in the high-accumulation Dome Summit South ice core, Law Dome, Antarctica, Ann. Glaciol., 27, 385-390, 1998.

Dalwadi, G., Benson, H. E., and Chen, Y.: Comparison of diafiltration and tangential flow filtration for purification of nanoparticle suspensions, Pharm. Res., 22, 2152-2162, doi:10.1007/s11095005-7781-z, 2005.

Edwards, R., Sedwick, P., Morgan, V., and Boutron, C.: Iron in ice cores from Law Dome: a record of atmospheric iron deposition for maritime East Antarctica during the Holocene and Last Glacial Maximum, Geochem. Geophy. Geosy., 7, Q12Q01, doi:10.1029/2006GC001307, 2006.

Etheridge, D., Steele, L., Langenfelds, R., Francey, R., Barnola, J. M., and Morgan, V.: Natural and anthropogenic changes in atmospheric $\mathrm{CO}_{2}$ over the last 1000 years from air in Antarctic ice and firn, J. Geophys. Res.-Atmos., 101, 4115-4128, 1996.

Flanner, M. G., Zender, C. S., Randerson, J. T., and Rasch, P. J.: Present-day climate forcing and response from black carbon in snow, J. Geophys. Res.-Atmos., 112, D11202, doi:10.1029/2006jd008003, 2007.

Giovannoni, S., DeLong, E., Schmidt, T., and Pace, N.: Tangential flow filtration and preliminary phylogenetic analysis of marine picoplankton, Appl. Environ. Microb., 56, 2572-2575, 1990.

Hansen, J. and Nazarenko, L.: Soot climate forcing via snow and ice albedos, P. Natl. Acad. Sci. USA, 101, 423-428, doi:10.1073/Pnas.2237157100, 2004.

Hegg, D. A., Warren, S. G., Grenfell, T. C., Doherty, S. J., Larson, T. V., and Clarke, A. D.: Source attribution of black carbon in Arctic snow, Environ. Sci. Technol., 43, 4016-4021, doi:10.1021/es803623f, 2009.

Hodnebrog, Ø., Myhre, G., and Samset, B. H.: How shorter black carbon lifetime alters its climate effect, Nat. Commun., 5, 6065, doi:10.1038/ncomms6065, 2014.

Holland, G. J.: Interannual variability of the Australian summer monsoon at Darwin: 1952-82, Mon. Weather Rev., 114, 594-604, doi:10.1175/15200493(1986)114<0594:IVOTAS>2.0.CO;2, 1986.

Jacobson, M. Z.: Strong radiative heating due to the mixing state of black carbon in atmospheric aerosols, Nature, 409, 695-697, 2001.

Johnson, B., Shine, K., and Forster, P.: The semi-direct aerosol effect: impact of absorbing aerosols on marine stratocumulus, Q. J. Roy. Meteor. Soc., 130, 1407-1422, 2004.

Johnson, D. W., Kilsby, C. G., McKenna, D. S., Saunders, R. W., Jenkins, G. J., Smith, F. B., and Foot, J. S.: Airborne observations of the physical and chemical characteristics of the Kuwait oil smoke plume, Nature, 353, 617-621, 1991.

Kaars, S. v. d., Wang, X., Kershaw, P., Guichard, F., and Setiabudi, D. A.: A Late Quaternary palaeoecological record from the Banda Sea, Indonesia: patterns of vegetation, climate and biomass burning in Indonesia and northern Australia, Palaeogeogr. Palaeocl., 155, 135-153, doi:10.1016/S00310182(99)00098-X, 2000. 
Koch, D., Schulz, M., Kinne, S., McNaughton, C., Spackman, J. R., Balkanski, Y., Bauer, S., Berntsen, T., Bond, T. C., Boucher, O., Chin, M., Clarke, A., De Luca, N., Dentener, F., Diehl, T., Dubovik, O., Easter, R., Fahey, D. W., Feichter, J., Fillmore, D., Freitag, S., Ghan, S., Ginoux, P., Gong, S., Horowitz, L., Iversen, T., Kirkevåg, A., Klimont, Z., Kondo, Y., Krol, M., Liu, X., Miller, R., Montanaro, V., Moteki, N., Myhre, G., Penner, J. E., Perlwitz, J., Pitari, G., Reddy, S., Sahu, L., Sakamoto, H., Schuster, G., Schwarz, J. P., Seland, Ø., Stier, P., Takegawa, N., Takemura, T., Textor, C., van Aardenne, J. A., and Zhao, Y: Evaluation of black carbon estimations in global aerosol models, Atmos. Chem. Phys., 9, 9001-9026, doi:10.5194/acp-9-9001-2009, 2009.

Li, J., Pósfai, M., Hobbs, P. V., and Buseck, P. R.: Individual aerosol particles from biomass burning in southern Africa: 2, Compositions and aging of inorganic particles, J. Geophys. Res.-Atmos., 108, 8484, doi:10.1029/2002JD002310, 2003.

Martins, J. V., Artaxo, P., Liousse, C., Reid, J. S., Hobbs, P. V., and Kaufman, Y. J.: Effects of black carbon content, particle size, and mixing on light absorption by aerosols from biomass burning in Brazil, J. Geophys. Res.-Atmos., 103, 32041-32050, 1998.

McConnell, J. R., Edwards, R., Kok, G. L., Flanner, M. G., Zender, C. S., Saltzman, E. S., Banta, J. R., Pasteris, D. R., Carter, M. M., and Kahl, J. D. W.: 20th-century industrial black carbon emissions altered arctic climate forcing, Science, 317, 1381-1384, doi:10.1126/Science.1144856, 2007.

Moffet, R. C. and Prather, K. A.: In-situ measurements of the mixing state and optical properties of soot with implications for radiative forcing estimates, P. Natl. Acad. Sci. USA, 106, 1187211877, 2009.

Murr, L. E., Esquivel, E. V., Bang, J. J., de la Rosa, G., and GardeaTorresdey, J. L.: Chemistry and nanoparticulate compositions of a 10,000 year-old ice core melt water, Water Res., 38, 42824296, doi:10.1016/J.Watres.2004.08.010, 2004.

Ohata, S., Moteki, N., and Kondo, Y.: Evaluation of a method for measurement of the concentration and size distribution of black carbon particles suspended in rainwater, Aerosol Sci. Tech., 45, 1326-1336, doi:10.1080/02786826.2011.593590, 2011.

Palmer, A. S., van Ommen, T. D., Curran, M. A., Morgan, V., Souney, J. M., and Mayewski, P. A.: High-precision dating of volcanic events (AD 1301-1995) using ice cores from Law Dome, Antarctica, J. Geophys. Res., 106, 28089, doi:10.1029/2001JD000330, 2001.

Pedro, J. B., McConnell, J. R., van Ommen, T. D., Fink, D., Curran, M. A. J., Smith, A. M., Simon, K. J., Moy, A. D., and Das, S. B.: Solar and climate influences on ice core $10 \mathrm{Be}$ records from Antarctica and Greenland during the neutron monitor era, Earth Planet. Sc. Lett., 355, 174-186, doi:10.1016/j.epsl.2012.08.038, 2012.

Plummer, C. T., Curran, M. A. J., van Ommen, T D., Rasmussen, S. O., Moy, A. D., Vance, T. R., Clausen, H. B., Vinther, B. M., and Mayewski, P. A.: An independently dated 2000 yr volcanic record from Law Dome, East Antarctica, including a new perspective on the dating of the 1450s CE eruption of Kuwae, Vanuatu, Clim. Past, 8, 1929-1940, doi:10.5194/cp-81929-2012, 2012.

Pósfai, M., Anderson, J. R., Buseck, P. R., and Sievering, H.: Soot and sulfate aerosol particles in the remote marine troposphere, J. Geophys. Res.-Atmos., 104, 21685-21693, 1999.
Rothenbacher, S., Messerer, A., and Kasper, G.: Fragmentation and bond strength of airborne diesel soot agglomerates, Particle and fibre toxicology, 5, 9, doi:10.1186/1743-8977-5-9, 2008.

Scarnato, B. V., China, S., Nielsen, K., and Mazzoleni, C.: Perturbations of the optical properties of mineral dust particles by mixing with black carbon: a numerical simulation study, Atmos. Chem. Phys., 15, 6913-6928, doi:10.5194/acp-15-6913-2015, 2015.

Schwarz, J., Gao, R., Fahey, D., Thomson, D., Watts, L., Wilson, J., Reeves, J., Darbeheshti, M., Baumgardner, D., and Kok, G.: Single-particle measurements of midlatitude black carbon and light-scattering aerosols from the boundary layer to the lower stratosphere, J. Geophys. Res.-Atmos., 111, D16207, doi:10.1029/2006JD007076, 2006.

Schwarz, J. P., Spackman, J. R., Gao, R. S., Watts, L. A., Stier, P., Schulz, M., Davis, S. M., Wofsy, S. C., and Fahey, D. W.: Global-scale black carbon profiles observed in the remote atmosphere and compared to models, Geophys. Res. Lett., 37, L18812, doi:10.1029/2010GL044372, 2010.

Schwarz, J. P., Gao, R. S., Perring, A. E., Spackman, J. R., and Fahey, D. W.: Black carbon aerosol size in snow, Sci. Rep., 3, 1356, doi:10.1038/srep01356, 2013.

Slowik, J. G., Cross, E. S., Han, J.-H., Davidovits, P., Onasch, T. B., Jayne, J. T., Williams, L. R., Canagaratna, M. R., Worsnop, D. R., and Chakrabarty, R. K.: An inter-comparison of instruments measuring black carbon content of soot particles, Aerosol Sci. Tech., 41, 295-314, 2007.

Stier, P., Seinfeld, J. H., Kinne, S., Feichter, J., and Boucher, O.: Impact of nonabsorbing anthropogenic aerosols on clear-sky atmospheric absorption, J. Geophys. Res.-Atmos., 111, D18201, doi:10.1029/2006JD007147 2006.

Stohl, A. and Sodemann, H.: Characteristics of atmospheric transport into the Antarctic troposphere, J. Geophys. Res.-Atmos., 115, D02305, doi:10.1029/2009jd012536, 2010.

Torres, A., Bond, T. C., Lehmann, C. M. B., Subramanian, R., and Hadley, O. L.: Measuring organic carbon and black carbon in rainwater: evaluation of methods, Aerosol Sci. Tech., 48, 239250, doi:10.1080/02786826.2013.868596, 2013.

Utsunomiya, S., and Ewing, R. C.: Application of highangle annular dark field scanning transmission electron microscopy, scanning transmission electron microscopy-energy dispersive X-ray spectrometry, and energy-filtered transmission electron microscopy to the characterization of nanoparticles in the environment, Environ. Sci. Technol., 37, 786-791, doi:10.1021/es026053t, 2003.

Vallelonga, P., Van de Velde, K., Candelone, J.-P., Morgan, V., Boutron, C., and Rosman, K.: The lead pollution history of Law Dome, Antarctica, from isotopic measurements on ice cores: 1500 AD to 1989 AD, Earth Planet. Sc. Lett., 204, 291-306, 2002.

van Ommen, T. D. and Morgan, V.: Peroxide concentrations in the Dome summit south ice core, Law Dome, Antarctica, J. Geophys. Res.-Atmos., 101, 15147-15152, 1996.

van Ommen, T. D. and Morgan, V.: Snowfall increase in coastal East Antarctica linked with southwest Western Australian drought, Nature Geosci., 3, 267-272, 2010.

Warren, S. G. and Clarke, A. D.: Soot in the atmosphere and snow surface of Antarctica, J. Geophys. Res.-Atmos., 95, 1811-1816, doi:10.1029/JD095iD02p01811, 1990. 